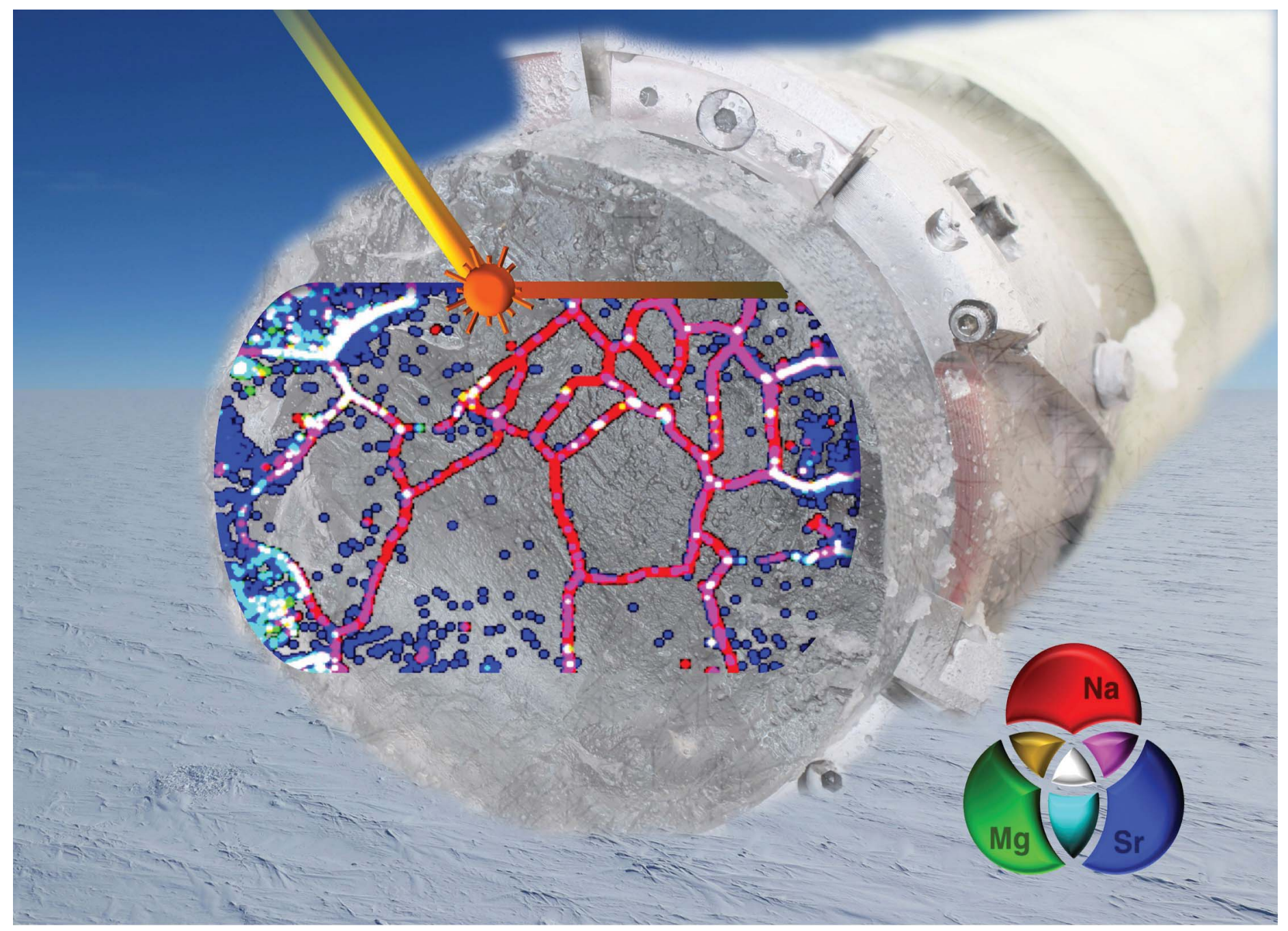

Showcasing research from Professor Barbante's laboratory, Department of Environmental Sciences, Informatics and Statistics, Ca'Foscari University of Venice, Italy.

Imaging the impurity distribution in glacier ice cores with LA-ICP-MS

Laser ablation inductively-coupled plasma mass spectrometry (LA-ICP-MS) offers micro-destructive, micron-scale geochemical analysis of glacier ice cores - one of the most significant climate archives. A novel setup for LA-ICP-MS ice core analysis achieves the first application of state-of-the-art imaging techniques to ice cores. Mapping the 2D impurity distribution reveals the imprint of ice crystal features in the high-resolution images, thus generating an improved understanding of the LA-ICP-MS signal origin in ice cores. Ultimately this sets a cornerstone for future LA-ICP-MS investigations of the oldest and highly thinned layers of ice cores.

\section{As featured in:}

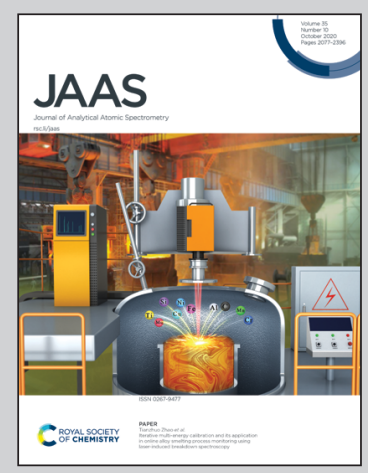

See Pascal Bohleber et al., J. Anal. At. Spectrom., 2020, 35, 2204. 


\title{
Imaging the impurity distribution in glacier ice cores with LA-ICP-MS
}

Cite this: J. Anal. At. Spectrom., 2020 35,2204

\begin{abstract}
Pascal Bohleber, (iD *a Marco Roman, (iD a Martin Šala (iD ${ }^{b}$ and Carlo Barbante (iD ac
Impurity records in polar ice cores have provided invaluable insights into atmospheric aerosol concentrations of the past environment. The investigation of the oldest, deepest and highly thinned ice core layers is one of the most pressing tasks in today's state-of-the-art ice core research. This calls for impurity analysis at high spatial resolution, which has to take into account post-depositional processes through the interaction of impurities with the ice matrix. To this end, the technique of laser ablation inductively-coupled plasma mass spectrometry (LA-ICP-MS) has shown great potential, which still remains to be fully exploited, however. Here we demonstrate how the application of LA-ICP-MS for imaging the impurity distribution in ice cores can be refined and strongly improved. A novel cryogenic two-volume ablation chamber is paired with a rapid aerosol transfer system in order to achieve fast washout times $(34 \mathrm{~ms})$. In so doing, we are able to analyze ice cores for the first time using next generation LA-ICP-MS imaging techniques. The improved LA-ICP-MS method for ice cores offers not only high scan speeds for single line profiles (around $1 \mathrm{~mm} \mathrm{~s}^{-1}$ ) but can also map the localization of impurities at high spatial resolution $(35 \mu \mathrm{m})$, at high speed and without imaging artifacts. This promises not only new insights into the impurity distribution in glacier ice but also lays the ground for an improved understanding of the LA-ICP-MS signal obtained from ice cores. As a result, LA-ICP-MS can deliver an

important contribution for retrieving future paleo-environmental records from highly thinned ice layers.
\end{abstract}

Received 16th April 2020

Accepted 25th June 2020

DOI: $10.1039 / \mathrm{d} 0 \mathrm{ja00170h}$

rsc.li/jaas

\section{Introduction}

Covering time-scales from decades to hundreds of millennia, ice cores represent one of the cornerstones in today's state-ofthe-art paleoclimate research. The investigation of the oldest, deepest and highly thinned ice core layers requires new highresolution techniques for their analysis. This is particularly the case regarding a 1.5 million year-old record soon to be recovered from Antarctica, with an expected sub-mm nominal annual layer thickness ${ }^{1}$ exceeding the resolution capabilities of standard methods. Originally pioneered for ice analysis almost two decades ago, ${ }^{2}$ laser ablation inductively-coupled plasma mass spectrometry (LA-ICP-MS) has recently re-emerged for high-resolution trace element characterization of ice cores..$^{3-5}$ Fundamental to establish the interpretation of the novel LAICP-MS signals was the comparison with standard techniques based on meltwater analysis, such as the continuous flow analysis (CFA). ${ }^{6,7}$ By this means, the consistency between the low frequency variability seen in LA-ICP-MS signals and the full resolution meltwater analysis was demonstrated, ${ }^{8,9}$ which was

\footnotetext{
${ }^{a}$ Department of Environmental Sciences, Informatics and Statistics, Ca'Foscari University of Venice, Italy.E-mail: pascal.bohleber@unive.it

${ }^{b}$ Department of Analytical Chemistry, National Institute of Chemistry, Ljubljana, Slovenia

'Institute of Polar Sciences, National Research Council of Italy, Venice, Italy
}

extended also to the detection of annual layers by means of LAICP-MS..$^{10}$ As a next step, achieving a full understanding of LAICP-MS signals, including the high-frequency components, calls for a dedicated assessment of their relation to ice crystal features. As a polycrystal, glacier ice generally consists of a large number of individual crystals (grains), as well as associated microscopic features such as grain boundaries and triple junctions (i.e. the intersection of grain boundaries). ${ }^{11}$ At a spatial resolution of more than $100 \mu \mathrm{m}$, it has already been suggested that the LA-ICP-MS signals are influenced by the presence of such ice crystal features. ${ }^{4,9,12,13}$ In turn, this implies that LA-ICP-MS can provide a tool for investigating the localization of impurities in the ice matrix, thereby supplementing established methods such as energy-dispersive X-ray spectroscopy, ${ }^{14,15}$ X-ray spectroscopy coupled with scanning electron microscopy ${ }^{16}$ and cryo-raman microscopy. ${ }^{17,18}$ Understanding impurity localization is not only significant regarding postdepositional alteration of ice core paleoclimate records ${ }^{19}$ but also for the deformational ${ }^{20}$ and dielectric properties ${ }^{21}$ of glacier ice. Recent advances in the laser ablation community have made LA-ICP-MS into a particularly powerful technique for fast imaging of comparatively large areas $(\mathrm{cm} \times \mathrm{cm})$. Crucial steps in this direction were the use of ablation cells dedicated to fast washout $^{22}$ as well as optimized lasing and ICP-MS settings in order to avoid imaging artifacts. ${ }^{23}$ Here we report on our approach to combine these state-of-the-art imaging techniques 
for the first time with a novel LA-ICP-MS setup dedicated to ice core analysis. We aim to improve LA-ICP-MS for high-speed, high-resolution impurity imaging on ice cores. Notably this does not require a matrix-matched calibration, a complex task for glacier ice. ${ }^{9}$ Through revealing the imprint of ice crystal features, our overarching goal is to achieve an improved understanding of the LA-ICP-MS impurity signals in ice cores. Ultimately, the LA-ICP-MS imaging technique may provide a refined tool to investigate the localization of impurities in ice at unprecedented spatial detail.

\section{Experimental}

\section{Instrumental setup}

The LA-ICP-MS setup employed comprises a Thermo iCAP-RQ quadrupole ICP-MS and a Teledyne CETAC Photon Machines Analyte Excite $\mathrm{ArF}^{*}$ excimer laser. The laser ablation system contains a HelEx II 2-volume ablation cell on a high-precision xy-stage. Helium was used as a carrier gas for aerosol transport from the sample surface to the ICP-MS, with flow rates for cell and inner cup tuned to maximize transport efficiency. As an important modification with respect to previous LA-ICP-MS studies performed on ice, the Aerosol Rapid Introduction System (ARIS) was integrated. The ARIS is an add-on for Teledyne CETAC Technologies laser ablation systems, capable of further enhancing the aerosol washout to the millisecond range. ${ }^{24}$ Before entering the plasma, the aerosol is additionally mixed with Ar as a make-up gas in the ARIS mixing bulb. The ICP-MS is equipped with quartz injector and torch, Ni cones and high sensitivity insert. The signal acquisition was performed in standard mode. Instrumental parameters were optimized for best sensitivity in the whole mass range, and minimum oxides $\left(<0.5 \%\right.$ as $\left.{ }^{232} \mathrm{Th}^{16} \mathrm{O} /{ }^{232} \mathrm{Th}\right)$ for NIST 612 glass ablated with fluence $6 \mathrm{~J} \mathrm{~cm}^{-2}$, spot size $85 \mu \mathrm{m}$ (circular), repetition rate $10 \mathrm{~Hz}$ and scan speed $5 \mu \mathrm{m} \mathrm{s}^{-1}$. The ICP-MS operating parameters adopted for ice analysis are reported in Table 1.

Regarding ice sample preparation and surface decontamination established procedures ${ }^{\mathbf{4 , 9}}$ were followed. A band saw was used in a cold-room $\left(-20^{\circ} \mathrm{C}\right)$ to cut ice samples to a strip geometry $(8 \times 2 \mathrm{~cm})$. Thickness was then reduced to $1.5 \mathrm{~cm}$ using a custom-built PTFE vice for ice scraping as well as manual scraping, both utilizing a ceramic $\mathrm{ZrO}_{2}$ blade (American Cutting Edge, USA). This included a fresh scraping for surface decontamination before placing the sample into the cryogenic sample holder and subsequent insertion into the HelEx II cell. The custom-designed cryogenic sample holder uses the circulation of a glycol-water mixture cooled to $-30{ }^{\circ} \mathrm{C}$ in a Julabo
F34 chiller (Julabo GmbH, Germany). The Helium used as carrier gas in the ablation cell is also pre-cooled through the same chiller. Aluminium sample trays can be exchanged for holding strips of ice, artificial ice standards and certified reference materials (CRMs) (Fig. 1). In order to avoid disturbance to the actual samples a thermocouple element was frozen into an additional artificial ice sample. The artifical ice surface temperature was monitored to remain at $-(18 \pm 2){ }^{\circ} \mathrm{C}$. This is within the range of typical in situ temperatures of ice in the deeper parts of the polar ice sheets. ${ }^{25}$

\section{Optimization for impurity imaging of ice cores}

Ablation of the NIST glasses served to set up the optimal washout profile. To estimate washout performance, a total of 55 individual spots $(35 \times 35 \mu \mathrm{m}$ squares) were ablated along the NIST 612 standard, monitoring ${ }^{238} \mathrm{U}$ at $1 \mathrm{~ms}$ dwell time. The average width of the peaks results in 27 and $34 \mathrm{~ms}$ washout time, evaluated using the 0.1 and 0.01 full width maximum criterion, respectively. The LA-ICP-MS parameters were adjusted following a recently established modelling approach to determine optimized data acquisition settings for avoiding imaging artifacts. ${ }^{26}$ The target total acquisition time (AT) for the ICP-MS mass analysis was defined to match the estimated washout. The repetition rate of the laser $f_{\mathrm{LA}}$ and the dosage where chosen to fulfill the criterion $\mathrm{AT} \times f_{\mathrm{LA}}=\mathbb{Z}^{+}\left(\mathbb{Z}^{+}\right.$being a positive integer $)$. In case of sequential scanning mass spectrometers such as quadrupoles, this adjustment between the laser and ICP-MS sampling frequency is crucial to avoid imaging artifacts related to aliasing effects. ${ }^{27}$ Accordingly, it was chosen to select $\mathrm{AT} \times f_{\mathrm{LA}}=10$. Table 2 summarizes the improved settings for data acquisition. Four elements were selected that (i) have significance as an ice core paleoclimate proxy but are not affected by known analytical challenges and (ii) showed a resolvable signal/background ratio. Specific isotopes were selected to avoid any spectral interferences and maximize sensitivity, and dwell times to be inversely proportional to the expected average signal intensity from the ice (in the present case specifically for Antarctic ice core samples). With respect to (ii), we found that ${ }^{23} \mathrm{Na},{ }^{25} \mathrm{Mg}$ and ${ }^{88} \mathrm{Sr}$ generally showed high signal/noise ratios and thus were measured in all acquisitions. Additional isotopes, ${ }^{55} \mathrm{Mn},{ }^{59} \mathrm{Co}$ or ${ }^{65} \mathrm{Cu}$, with a comparatively lower signal/noise ratio were also selected. Notably, a special reason for including $\mathrm{Na}$ concerns its known probability to be located at grain boundaries. ${ }^{16}$ In the present framework, this affinity makes $\mathrm{Na}$ a particularly interesting element to investigate the imprint of ice crystal features on the LA-ICP-MS signal.

Table 1 General settings and operating parameters of the LA-ICP-MS system

$\begin{array}{lll}\text { ICP-MS Laser } & \end{array}$

Instrument

RF power

Cooling gas flow

Auxiliary gas flow

Ar makeup gas flow
Thermo iCAP-RQ

$1550 \mathrm{~W}$

$14 \mathrm{~L} \mathrm{~min}^{-1}$

$0.8 \mathrm{~L} \mathrm{~min}^{-1}$

$0.8 \mathrm{~L} \mathrm{~min}^{-1}$
Instrument

Laser type

He gas flow cell

He gas flow cup

Transfer line
Teledyne analyte excite ArF excimer $193 \mathrm{~nm}$

$0.25 \mathrm{~L} \mathrm{~min}^{-1}$

$0.25 \mathrm{~L} \mathrm{~min}^{-1}$

ARIS 


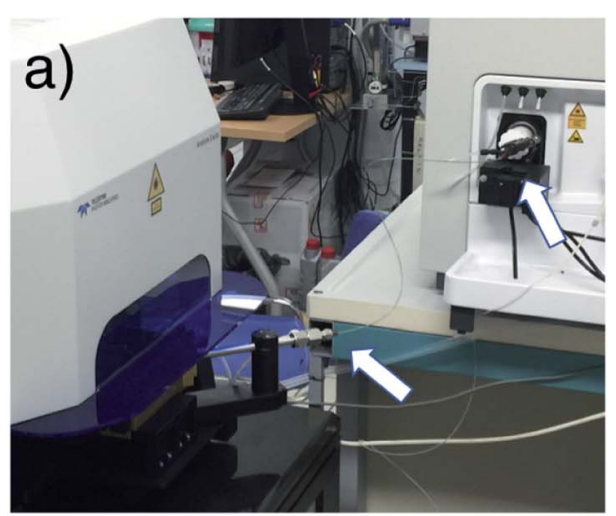

C)
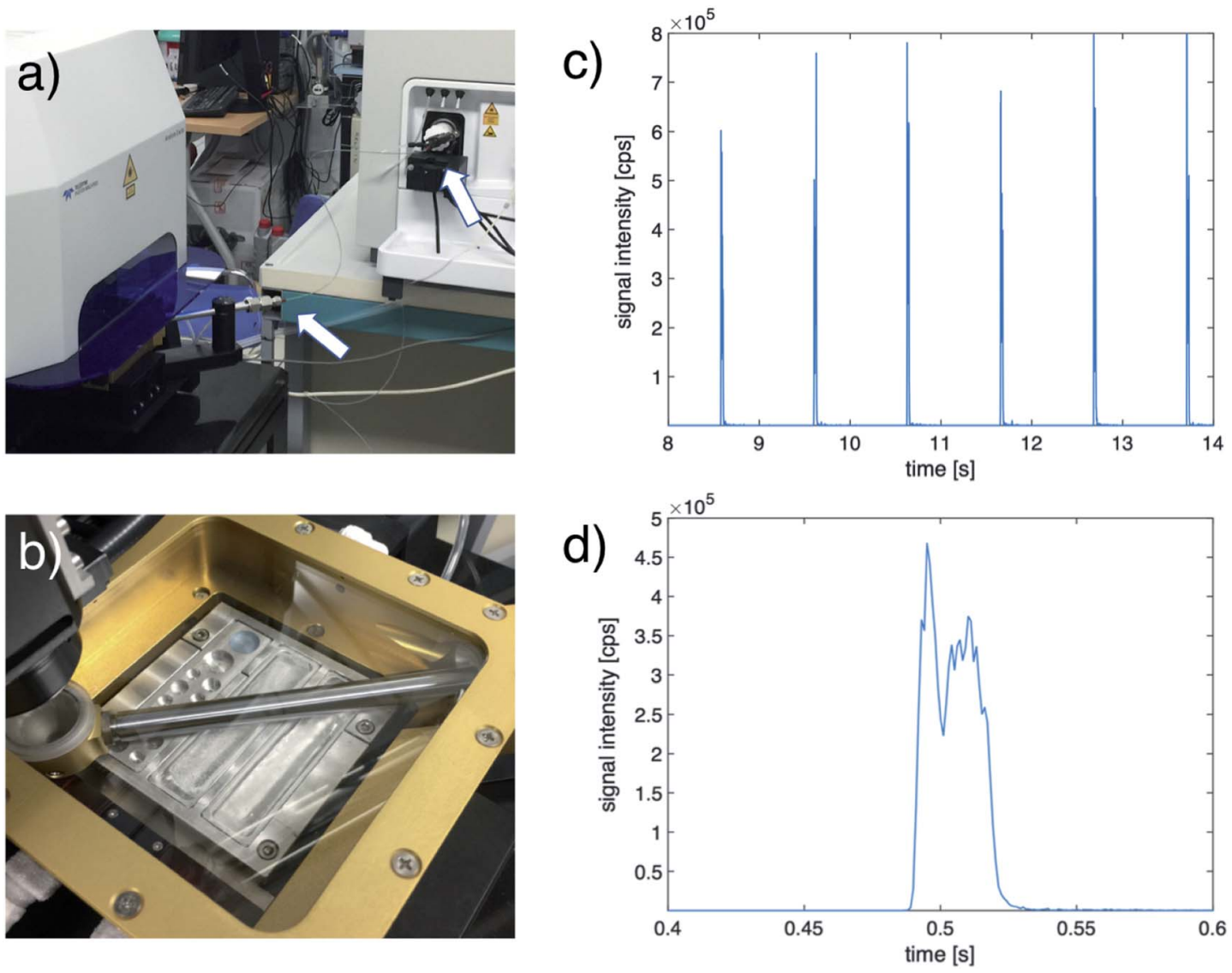

Fig. 1 Illustration of the instrumental setup (left column) and washout performance (right column). The LA-ICP-MS setup for ice core analysis at Ca'Foscari University of Venice especially includes: (a) the ARIS (white arrows), (b) a custom-designed cryogenic sample holder. Aluminium sample trays could be exchanged for holding strips of ice artificial ice samples and NIST glass CRMs. Transport efficiency performances corresponding to a washout time of around $34 \mathrm{~ms}$ are illustrated in (c) showing the typical ICP-MS signal of ${ }^{238} \mathrm{U}$ for repeated single spot ablations of NIST 612, leading to the average peak shape in (d).

Table 2 Optimized LA-ICP-MS acquisition parameters for ice impurity imaging

\begin{tabular}{llll}
\hline ICP-MS & \multicolumn{3}{c}{ Laser } \\
\hline Analytes & $\begin{array}{l}\text { Dwell } \\
\text { times [ms] }\end{array}$ & Fluence & $3.5 \mathrm{~J} \mathrm{~cm}^{-2}$ \\
& 4 & Spot size & $35 \mu \mathrm{m}$ square \\
${ }^{23} \mathrm{Na}$ & 4.6 & Washout time & $34 \mathrm{~ms}$ \\
${ }^{25} \mathrm{Mg}$ & 10 & Ablation mode & Fixed dosage \\
${ }^{88} \mathrm{Sr}$ & 10 & Dosage & 10 \\
${ }^{55} \mathrm{Mn},{ }^{59} \mathrm{Co}$ or ${ }^{65} \mathrm{Cu}$ & Repetition rate & $294 \mathrm{~Hz}$ \\
Acquisition time & 34 & &
\end{tabular}

Elemental maps are acquired as a pattern of lines, with dosage 10 (i.e. 10 overlaps of shots in scan direction). Perpendicular to the scan directions, individual lines do not overlap. A full pre-ablation run was conducted using identical laser settings but a larger spot size of $150 \mu \mathrm{m}$ square as well as bidirectional scanning. The preablation runs consumed about $10 \%$ of the time needed for the actual measurement. Data elaboration comprised synchronization of the ICP-MS and laser log data, background removal and image construction. These steps were performed using the software HDIP (Teledyne Photon Machines, Bozeman, MT, USA).

The ice sample analyzed for developing the proposed imaging method was obtained from the Talos Dome ice core, drilled in East Antarctica. ${ }^{28}$ The sample is from bag 375-B1 and has an approximate age of 5000 years. For this section of the Talos Dome ice core, a typical size of an ice crystal is around 1-2 $\mathrm{mm} .^{29}$

\section{Results and discussion}

\section{Improved impurity imaging on ice cores with LA-ICP-MS}

In previous LA-ICP-MS ice core applications, the $193 \mathrm{~nm}$ wavelength of the excimer laser has been demonstrated to produce controlled ablation of glacier ice at fluences around $3.5 \mathrm{~J} \mathrm{~cm}^{-2}$, with visibly smooth and well-defined craters around $100 \mu \mathrm{m}$ deep. ${ }^{3}$ A direct comparison in ablation performance between previous ${ }^{3}$ and the present setup is not straightforward, however, due to differences in the laser systems, for instance concerning the laser pulse width. Most setups for ice core analysis used ablation cells with around $1 \mathrm{~s}$ or higher washout time, ${ }^{\mathbf{4 , 8 , 9}}$ which is principally determined by the extraction of aerosol from the 
ablation cell and subsequent dispersion in the transfer line. For washout times in the range of seconds, single laser pulses cannot be resolved, except for pulse rates of a few Hz. Mostly used were repetition rates in the range $10-20 \mathrm{~Hz}$, which produce a continuous LA-ICP-MS signal for line scanning with such washout times. In the present work the previous applications were followed regarding choice of laser and fluence, but taking a different approach by achieving a faster washout time. This choice was motivated by recent developments in LA-ICP-MS providing refinements in instrumentation, optimization of measurement and post-acquisition procedures, and in particular low-dispersion ablation cells with optimized flow dynamics. With washout times in the ms range, the recording of baseline-separated single pulses at high repetition rates became the new basis of 2D LA-ICP-MS imaging, generating maps with higher spatial resolution, higher sensitivity, quicker analysis, and lower noise. ${ }^{22,30,31}$ Fast washout cells have been shown to remedy image distortion, also in continuous scanning mode, ${ }^{32,33}$ which can manifest through "halo effects" and "smearing", as well as instrument (Flicker and Poisson) noise that adds up with other artifacts to worsen image quality.

Fig. 2 illustrates the benefit of transferring this optimized imaging techniques to the analysis of ice cores by comparing two images recorded with and without the improved settings (Table 2). The "original" parameters included a "slow" wash out of $0.5 \mathrm{~s}$, corresponding to the performance of the standard transfer line, as well as a $150 \mu \mathrm{m}$ square, $100 \mathrm{~Hz}$ repetition rate and $200 \mu \mathrm{m} \mathrm{s}^{-1}$ scan speed. Fig. 2 also includes mosaics obtained from stacked snapshots of the laser camera, thus showing features visible on the ice surface such as air bubbles (dark circles) and grain boundaries (dark lines). While some common features can be discerned between the original LA-ICPMS image and the mosaic, the most evident feature is clearly the amount of "smearing" along the scan direction from left to right. The improved settings result in a LA-ICP-MS image that is completely free of the "smearing" and shows clear similarity in its features with the ice surface features captured by the mosaic image.

Since being inevitably linked to analysing the surface of a sample, LA-ICP-MS is sensitive to contamination and surface effects. Regarding surface contamination, the present work followed previous developments, which have addressed this challenge via rigorous surface decontamination. ${ }^{4,5}$ The potential for artifact generation in sample surface preparation has been observed in scanning electron microscopy. ${ }^{\mathbf{1 4}}$ In particular at grain boundaries, sublimation may increase the concentration of already present impurities. ${ }^{34}$ Sublimation has also been observed to increase concentrations of some impurities at triple junctions. ${ }^{16}$ Although in the present approach sample preparation did not include a dedicated sublimation period, sublimation was also expected to occur within the He atmosphere in the ablation chamber. Based on visual inspection of the ice surface as seen in the laser camera, grain boundaries become more clearly visible within the first few minutes inside the ablation cell, but no distinct changes of the grain boundaries were seen over longer time periods (i.e. hours). As an example, the two mosaics in Fig. 2 (lower left) and Fig. 3 were recorded within about 5 hours. Fig. 3 also allows a preliminary inspection for triple junctions coinciding with bright spots in the LA-ICP- a) Improved

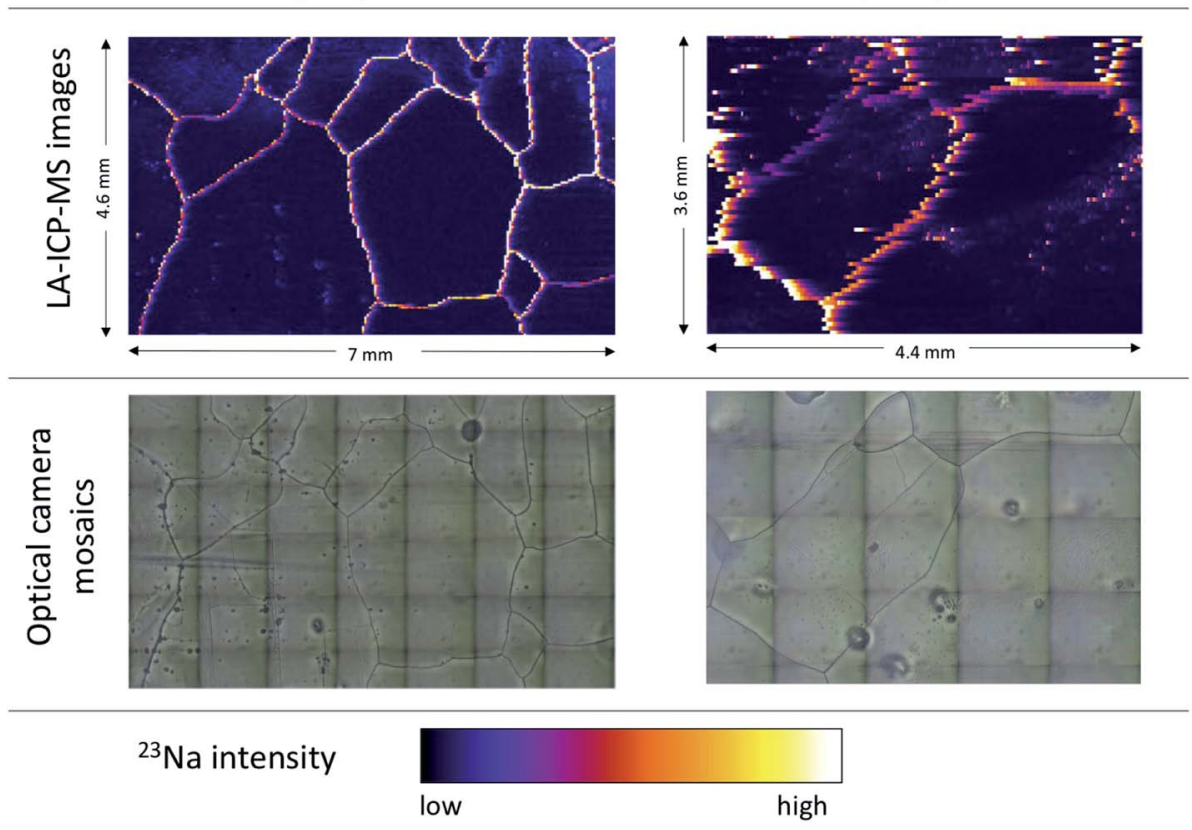

Fig. 2 Illustration of imaging quality for ${ }^{23} \mathrm{Na}$ produced with (column (a)) and without our improved settings (see text, column (b)), for two different ice core sections. For comparison, the lower row shows mosaics obtained from images of the laser camera. Clearly visible are air bubbles (dark circles) and grain boundaries (dark lines). 


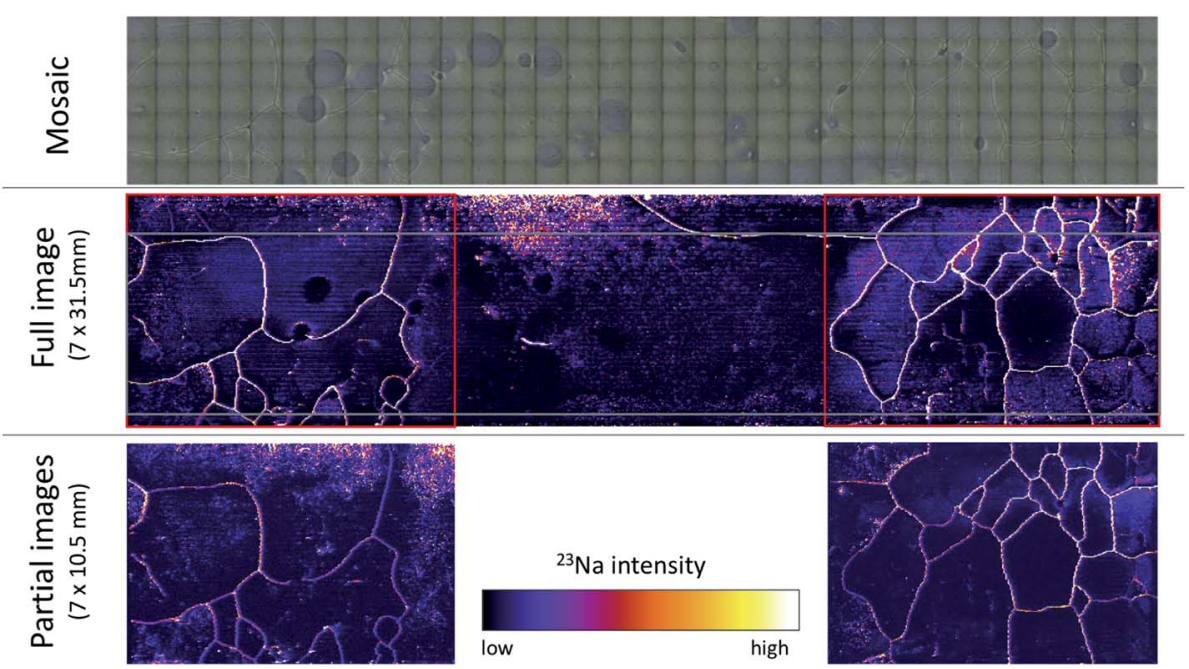

Fig. 3 Full image of ${ }^{23} \mathrm{Na}$ intensities over $7 \times 31.5 \mathrm{~mm}$ in a sample of the Talos Dome ice core, Antarctica (middle row). For comparison, the top row shows the mosaic of image of the laser camera, its position being indicated by the gray square in the full image. Note air bubbles (dark circles) and grain boundaries (dark lines). The main core axis runs from left to right (towards top of the core). Also shown are two partial images of the same sample, obtained from separate experiments and sample preparation (bottom). Red squares denote the position of the partial images within the full image. Note the reproducible main features among the images clearly showing a localization of $\mathrm{Na}$ at grain boundaries.

MS image, but no such evidence of increased impurity levels at triple junctions was found.

Considering that contamination and changes in surface properties would arguably lead to decreased image reproducibility, three consecutive images of the same ice sample were obtained. First two partial images were acquired, then after surface decontamination and pre-ablation a new image of a large area comprising the two partial images was obtained. Exemplarily shown in Fig. 3 for ${ }^{23} \mathrm{Na}$, a very high degree of reproducibility, and in particular all main characteristics of the previous images could be reliably reproduced. We can thus conclude that the surface properties do not change significantly over the characteristic time period for producing larger images.

Worth noting in this context, the scan speed employed in the present work (around $1030 \mu \mathrm{m} \mathrm{s}^{-1}$ ) is roughly 20 times higher with respect to previous LA-ICP-MS studies on ice cores. ${ }^{9}$ The high speed translates into the ability to obtain images over large areas within a feasible amount of time. For a $35 \mu \mathrm{m}$ beam size, the recording of a $7 \times 10.5 \mathrm{~mm}$ image requires 200 horizontal lines, corresponding to 1.8 million individual laser shots fired. With unidirectional measurements the recording takes around 2.5 hours, although imaging time can be reduced further by scanning in bidirectional mode (in the present case typically by about $30 \%$ ). Being able to cover areas of square $\mathrm{cm}$ in a comparatively short amount of time already illustrates the key strength of LA-ICP-MS imaging of ice, but also in a broader context of chemical imaging of environmental samples. ${ }^{35}$

Considering further the state-of-the-art in LA-ICP-MS analysis for ice cores, recent progress has been made to tackle achieving a robust matrix-matched calibration using artificial ice standards for quantitative analysis. ${ }^{9}$ While this is generally an important addition to the technique, imaging the localization of impurities does not require a fully quantitative method.
Instead, in this case achieving the highest possible spatial resolution while avoiding the generation of image artifacts is key. We have thus focused our attention on advancing this aspect of the technique. Previous attempts at co-evaluating the LA-ICP-MS signals in relation to the ice crystal structure have avoided imaging artifacts by using static laser drilling and subsequent spatial interpolation. However, the use of laser spots greater than $200 \mu \mathrm{m}$ imposed limits to investigate ice surface features in the micron-range and smaller. Nonetheless, the coarse resolution findings suggested that generally high concentration areas are found in the proximity of grain boundaries and triple junction, mostly for $\mathrm{Na}$ and $\mathrm{Mg} .{ }^{4,9} \mathrm{Here}$, it was possible to increase the spatial resolution by about one order of magnitude for ice core analysis: with no overlap in the vertical direction (perpendicular to the scan direction from left to right) the vertical resolution was determined by the laser spot size, in this case $35 \mu \mathrm{m}$. Along the scan direction, with the optimized combination of washout and acquisition time (34 $\mathrm{ms})$, laser repetition rate $(294 \mathrm{~Hz})$ and dosage (10), the resulting horizontal resolution was nearly identical. Notably, for comparatively abundant elements such as $\mathrm{Na}$ the beam size could be reduced further in order to increase spatial resolution while still providing enough sensitivity for Na detection by ICPMS. However, this would also increase the number of lines and thus the total measurement time, which calls for making a trade-off between resolution and measurement time. In this respect we found that the instrumental settings used are generally adequate for mapping the impurity distribution in ice at sufficient spatial detail and moderate time consumption.

\section{Implications for future LA-ICP-MS analysis in ice cores}

For the example of Na, Fig. 3 demonstrates how the LA-ICP-MS imaging technique allows to study the localization of impurities 

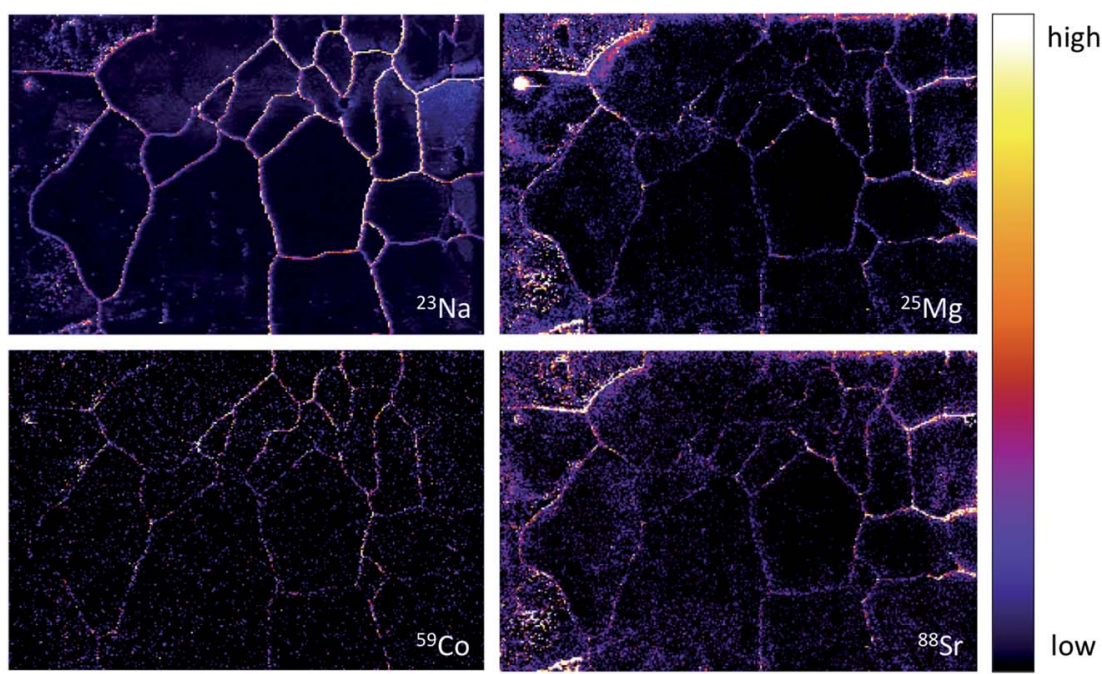

Fig. 4 Illustration of differences in impurity localization for ${ }^{23} \mathrm{Na},{ }^{25} \mathrm{Mg},{ }^{59} \mathrm{Co}$ and ${ }^{88} \mathrm{Sr}$. The image corresponds to the partial image shown in the lower right of Fig. 3, covering $7 \times 10.5 \mathrm{~cm}$. Note that $\mathrm{Na}$ is localized at grain boundaries to a comparatively higher degree than $\mathrm{Mg}$ and $\mathrm{Sr}$, which also show high intensities at grain interiors

in the ice matrix, and their distribution over comparatively large areas. Fig. 4 provides a closer view at similarities and differences in the localization of four impurities. Owed to the high resolution and the absence of image artifacts in this method, the correlation between high Na intensity and locations of grain boundaries is now unequivocal for the first time. This is consistent with the already known trend of $\mathrm{Na}$ to localize at grain boundaries. ${ }^{16}$ Notably, it has been found that the correlation with grain boundaries also holds generally for the intensities of the other impurities, although for $\mathrm{Mg}$ and $\mathrm{Sr}$ high intensities were also observed within individual grains. Regarding $\mathrm{Na}$ and $\mathrm{Mg}$, our findings corroborate previous indications from coarser resolution LA-ICP-MS imaging (although based on glacial period ice from Greenland). ${ }^{4,9}$ In a preliminary interpretation we can conclude that, at least in this section of the sample, $\mathrm{Na}$, Co and to a lesser degree $\mathrm{Mg}$ an $\mathrm{Sr}$ showed localization at grain boundaries, which may depend on their individual mobilities in the ice matrix and warrants further investigation.

Of special interest are the consequences of the impurity localization with respect to the interpretation of individual LAICP-MS profiles, i.e. single lines measured along the main core axis, which have been used so far to obtain a high-resolution time series of paleoclimate signals. ${ }^{36}$ From images obtained in the present study it was found that if a trace element is localized around grain boundaries, the grain boundary network strongly affects at least the high-frequency variability of the LA-ICP-MS signal. For better illustration, Fig. 5 shows a comparison of an individual line profile taken (arbitrarily) at the center of the full $\mathrm{Na}$ image of Fig. 3. Individual peaks occurring when the laser beam intersects a grain boundary are the basis of the agreement found between the LA-ICP-MS images and the ice surface features in the camera mosaics. This becomes evident from the peaks in the line profile corresponding to the intersections of the profile with grain boundaries (blue line in Fig. 5). In order to mimic the signal obtained from a coarser, approximately $200 \mu \mathrm{m}$ resolution, line profile, six adjacent lines were stacked (red box in the full image) and subsequently smoothed with a Gaussian filter (200 $\mu \mathrm{m}$ kernel). The resulting profile (red line) still shows some, much less apparent, imprint of the grain boundaries. Taking the full vertical average of the image (stacking all 200 lines, gray box in full image) erases the association of intensity peaks with grain boundaries. Smoothing at a corresponding $7 \mathrm{~mm}$ resolution resembles only the overall intensity gradient of the image. At this scale, the comparison with meltwater analyses had previously demonstrated the agreement with low-frequency signal components in LA-ICP-MS data. ${ }^{8,9}$ Accordingly it becomes evident that the imaging performed in the present work revealed the underlying origin of the LA-ICP-MS signals in profiles of coarser resolution. At least at the spatial resolution afforded in the present study, the spatial significance of a single profile along the main core axis is questionable.

Regarding its potential to reveal not only LA-ICP-MS signal formation but also the localization of impurities, the new imaging approach can be a crucial tool to investigate paleoclimate signals, and their preservation, in ice cores. Notably, the analysis over the entire core depth would not be needed. Already the analysis of exemplary sections with the present method would constitute an advance to investigate the spatial impurity distribution, e.g. in various climatic periods and especially in deep ice core sections. In their deepest and oldest parts, mean grain sizes in polar ice cores can reach several $\mathrm{cm} .{ }^{37}$ In those cases, a raster of spots is clearly too time consuming to be feasible, hence calling for mapping over areas of $\mathrm{mm}$ to $\mathrm{cm}$ in size with the present approach. At the same time, LA-ICP-MS imaging continues to evolve, with even sub- $\mu$ m imaging now at reach..$^{38}$ The potential for further increased repetition rates, ${ }^{39}$ accompanied by high scan speed and ultra-fast washout could render the imaging of even larger areas in ice cores feasible in the future. 


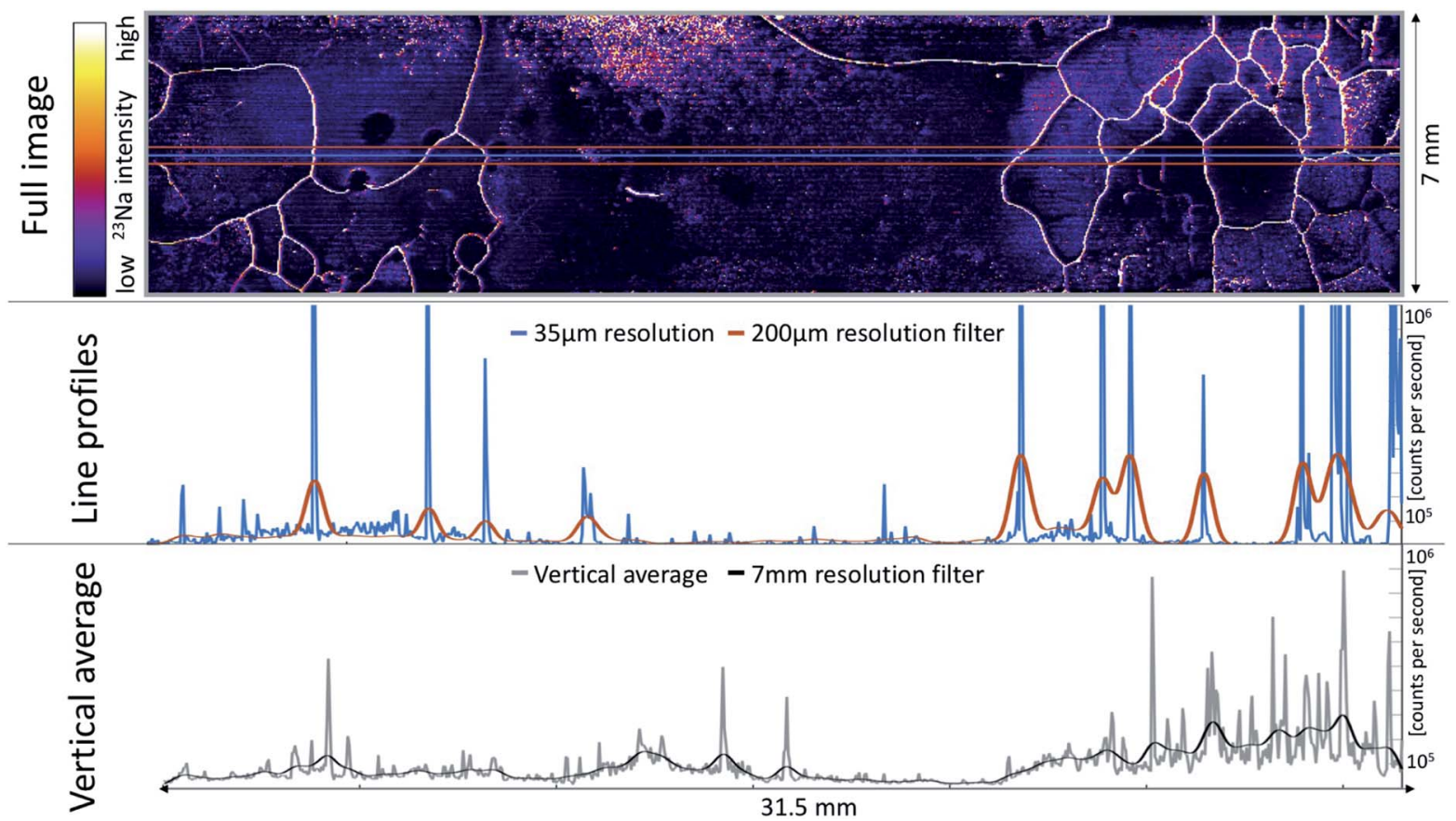

Fig. 5 Illustration of differences in continuous line profiles at different spatial resolution. All line profiles are obtained from sub-sampling the underlying dataset of the ${ }^{23} \mathrm{Na}$ image (see text). Only in the original profile at $35 \mu \mathrm{m}$ resolution, individual peaks can be associated clearly with the intersections of the profile with grain boundaries. Note that the line profiles (middle row) do not show the entire intensity scale for better visibility of the lower resolution data.

\section{Conclusions}

The new method advances the key strength of LA-ICP-MS as a technique to study ice impurity localization, namely its high speed, high spatial resolution and highest image quality. The rapid aerosol transfer affords high scan speeds in LA-ICP-MS analysis, which, in case of ice core applications, is higher by one order of magnitude than before. ${ }^{5,9}$ The scan speed afforded by the fast washout technology allows line profiles at speeds comparable to existing melting techniques optimized for acquisition of transient signals in ice cores. This could be also beneficial for high speed impurity profiling by continuous line measurements along the main ice core axis. However, as shown in the present work, the higher resolution also raises questions concerning the spatial representativity of single LA-ICP-MS profiles, hence calling for a dedicated investigation of this issue. In the context of future applications, next steps concern the imaging analysis of ice core samples over various depth ranges and climatic periods, targeting the wider investigation also of potential additional elements with paleoclimatic significance. Of additional interest is to perform an intermethod comparison of impurity localization on the same ice samples to obtain additional validation of the new method. If combined with sophisticated large volume cryo-holders for meter-long rods of ice, ${ }^{5}$ the LA-ICP-MS technology may eventually surpass both in speed and spatial resolution existing melting techniques optimized for acquisition of transient signals in ice cores. ${ }^{40}$ Through advancing our understanding of the signal constraints arising from the ice microstructure, results of the present work set a cornerstone to tap the full potential of LA-ICP-MS for investigating past environmental signals archived in the oldest and highly thinned layers of ice cores.

\section{Conflicts of interest}

There are no conflicts to declare.

\section{Acknowledgements}

The authors thank Ciprian Stremtan and Stijn van Malderen for their technical support. Likewise we thank Alessandro Bonetto for support in the laboratory. This publication also benefited from support by Barbara Delmonte and Barbara Stenni. PB gratefully acknowledges funding from the European Union's Horizon 2020 research and innovation programme under the Marie Skłodowska-Curie grant agreement No. 790280. MS acknowledges support from the Slovenian Research Agency (ARRS), contract number P1-0034. ELGA LabWater is acknowledged for providing the PURELAB Option-Q and Ultra Analytic systems which produced the ultrapure water used for cleaning and decontamination. This publication was generated in the frame of Beyond EPICA. The project has received funding from the European Union's Horizon 2020 research and innovation programme under grant agreement No. 815384 (Oldest Ice Core). It is supported by national partners and funding agencies in Belgium, Denmark, France, Germany, Italy, Norway, Sweden, Switzerland, The Netherlands and the United Kingdom. Logistic 
support is mainly provided by PNRA and IPEV through the Concordia Station system. The opinions expressed and arguments employed herein do not necessarily reflect the official views of the European Union funding agency or other national funding bodies. This is Beyond EPICA publication number 10 . The three anonymous referees are acknowledged for their comments which helped to improve the manuscript.

\section{References}

1 H. Fischer, J. Severinghaus, E. Brook, E. Wolff and M. Albert, Where to find 1.5 million yr old ice for the IPICS" Oldest Ice" ice core, Clim. Past, 2013, 9, 2489-2505.

2 H. Reinhardt, M. Kriews, H. Miller, O. Schrems, C. Lüdke, E. Hoffmann and J. Skole, Laser ablation inductively coupled plasma mass spectrometry: a new tool for trace element analysis in ice cores, Fresenius' J. Anal. Chem., 2001, 370, 629-636.

3 W. Müller, J. M. G. Shelley and S. O. Rasmussen, Direct chemical analysis of frozen ice cores by UV-laser ablation ICPMS, J. Anal. At. Spectrom., 2011, 26, 2391-2395.

4 D. Della Lunga, W. Müller, S. O. Rasmussen and A. Svensson, Location of cation impurities in NGRIP deep ice revealed by cryo-cell UV-laser-ablation ICPMS, J. Glaciol., 2014, 60, 970988.

5 S. B. Sneed, P. A. Mayewski, W. Sayre, M. J. Handley, A. V. Kurbatov, K. C. Taylor, P. Bohleber, D. Wagenbach, T. Erhardt and N. E. Spaulding, New LA-ICP-MS cryocell and calibration technique for sub-millimeter analysis of ice cores, J. Glaciol., 2015, 61, 233-242.

6 R. Röthlisberger, M. Bigler, M. Hutterli, S. Sommer, B. Stauffer, H. G. Junghans and D. Wagenbach, Technique for continuous high-resolution analysis of trace substances in firn and ice cores, Environ. Sci. Technol., 2000, 34, 338-342.

7 P. R. Kaufmann, U. Federer, M. A. Hutterli, M. Bigler, S. Schüpbach, U. Ruth, J. Schmitt and T. F. Stocker, An improved continuous flow analysis system for highresolution field measurements on ice cores, Environ. Sci. Technol., 2008, 42, 8044-8050.

8 N. E. Spaulding, S. B. Sneed, M. J. Handley, P. Bohleber, A. V. Kurbatov, N. J. Pearce, T. Erhardt and P. A. Mayewski, A New Multielement Method for LA-ICP-MS Data Acquisition from Glacier Ice Cores, Environ. Sci. Technol., 2017, 51, 13282-13287.

9 D. Della Lunga, W. Müller, S. O. Rasmussen, A. Svensson and P. Vallelonga, Calibrated cryo-cell UV-LA-ICPMS elemental concentrations from the NGRIP ice core reveal abrupt, subannual variability in dust across the GI-21.2 interstadial period, Cryosphere, 2017, 11, 1297-1309.

10 P. Bohleber, T. Erhardt, N. Spaulding, H. Hoffmann, H. Fischer and P. Mayewski, Temperature and mineral dust variability recorded in two low-accumulation Alpine ice cores over the last millennium, Clim. Past, 2018, 14, 21-37.

11 S. H. Faria, I. Weikusat and N. Azuma, The microstructure of polar ice. Part II: State of the art, J. Struct. Geol., 2014, 61, 2149.
12 T. M. Beers, S. B. Sneed, P. A. Mayewski, A. V. Kurbatov and M. J. Handley, Triple Junction and Grain Boundary Influences on Climate Signals in Polar Ice, arXiv preprint arXiv:2005.14268, 2020.

$13 \mathrm{~J}$. K. Kerch, Crystal-orientation fabric variations on the $\mathrm{cm}$ scale in cold Alpine ice: Interaction with paleo-climate proxies under deformation and implications for the interpretation of seismic velocities, PhD thesis, Heidelberg University, 2016.

14 P. R. Barnes, E. W. Wolff, D. C. Mallard and H. M. Mader, SEM studies of the morphology and chemistry of polar ice, Microsc. Res. Tech., 2003, 62, 62-69.

15 D. Iliescu and I. Baker, Effects of impurities and their redistribution during recrystallization of ice crystals, $J$. Glaciol., 2008, 54, 362-370.

16 P. R. Barnes and E. W. Wolff, Distribution of soluble impurities in cold glacial ice, J. Glaciol., 2004, 50, 311-324.

17 J. Eichler, C. Weikusat, A. Wegner, B. Twarloh, M. Behrens, H. Fischer, M. Hörhold, D. Jansen, S. Kipfstuhl, U. Ruth, et al., Impurity analysis and microstructure along the climatic transition from MIS 6 into 5e in the EDML ice core using cryo-Raman microscopy, Front. Earth Sci., 2019, $7,20$.

18 T. Sakurai, H. Ohno, S. Horikawa, Y. Iizuka, T. Uchida, K. Hirakawa and T. Hondoh, The chemical forms of watersoluble microparticles preserved in the Antarctic ice sheet during Termination I, J. Glaciol., 2011, 57, 1027-1032.

19 A. Rempel, E. Waddington, J. Wettlaufer and M. Worster, Possible displacement of the climate signal in ancient ice by premelting and anomalous diffusion, Nature, 2001, 411, 568-571.

20 D. Dahl-Jensen, T. Thorsteinsson, R. Alley and H. Shoji, Flow properties of the ice from the Greenland Ice Core Project ice core: the reason for folds?, J. Geophys. Res.: Oceans, 1997, 102, 26831-26840.

21 D. E. Stillman, J. A. MacGregor and R. E. Grimm, The role of acids in electrical conduction through ice, J. Geophys. Res.: Earth Surf., 2013, 118, 1-16.

22 H. A. Wang, D. Grolimund, C. Giesen, C. N. Borca, J. R. ShawStewart, B. Bodenmiller and D. Günther, Fast chemical imaging at high spatial resolution by laser ablation inductively coupled plasma mass spectrometry, Anal. Chem., 2013, 85, 10107-10116.

23 J. T. van Elteren, V. S. Šelih and M. Šala, Insights into the selection of 2D LA-ICP-MS (multi) elemental mapping conditions, J. Anal. At. Spectrom., 2019, 34, 1919-1931.

24 T. Van Acker, S. Van Malderen, T. Buckle and F. Vanhaecke, High-speed sub-micrometer imaging of sub-cellular structures in single cells using ARIS, Application Note Teledyne CETAC Technologies, 2017.

25 S. J. Johnsen, D. Dahl-Jensen, W. Dansgaard and N. Gundestrup, Greenland palaeotemperatures derived from GRIP bore hole temperature and ice core isotope profiles, Tellus B, 1995, 47, 624-629.

26 J. T. van Elteren, M. Šala and V. S. Šelih, Perceptual Image Quality Metrics Concept in Continuous Scanning 2D Laser 
Ablation-Inductively Coupled Plasma Mass Spectrometry Bioimaging, Anal. Chem., 2018, 90, 5916-5922.

27 J. T. van Elteren, V. S. Šelih, M. Šala, S. J. Van Malderen and F. Vanhaecke, Imaging artifacts in continuous scanning 2D LA-ICPMS imaging due to nonsynchronization issues, Anal. Chem., 2018, 90, 2896-2901.

28 D. Buiron, J. Chappellaz, B. Stenni, M. Frezzotti, M. Baumgartner, E. Capron, A. Landais, B. LemieuxDudon, V. Masson-Delmotte, M. Montagnat, et al., TALDICE-1 age scale of the Talos Dome deep ice core, East Antarctica, Clim. Past, 2011, 7, 1-16.

29 M. Montagnat, D. Buiron, L. Arnaud, A. Broquet, P. Schlitz, R. Jacob and S. Kipfstuhl, Measurements and numerical simulation of fabric evolution along the Talos Dome ice core, Antarctica, Earth Planet. Sci. Lett., 2012, 357, 168-178.

30 S. J. Van Malderen, J. T. van Elteren and F. Vanhaecke, Development of a fast laser ablation-inductively coupled plasma-mass spectrometry cell for sub- $\mu \mathrm{m}$ scanning of layered materials, J. Anal. At. Spectrom., 2015, 30, 119-125.

31 J. T. van Elteren, A. Izmer, V. S. Šelih and F. Vanhaecke, Novel image metrics for retrieval of the lateral resolution in line scan-based 2D LA-ICPMS imaging via an experimental-modeling approach, Anal. Chem., 2016, 88, 7413-7420.

32 S. J. Van Malderen, A. J. Managh, B. L. Sharp and F. Vanhaecke, Recent developments in the design of rapid response cells for laser ablation-inductively coupled plasma-mass spectrometry and their impact on bioimaging applications, J. Anal. At. Spectrom., 2016, 31, 423-439.
33 S. J. Van Malderen, E. Vergucht, M. De Rijcke, C. Janssen, L. Vincze and F. Vanhaecke, Quantitative determination and subcellular imaging of $\mathrm{Cu}$ in single cells via laser ablation-ICP-mass spectrometry using high-density microarray gelatin standards, Anal. Chem., 2016, 88, 57835789.

34 I. Baker and D. Cullen, SEM/EDS observations of impurities in polar ice: artifacts or not?, J. Glaciol., 2003, 49, 184-190.

35 F. Adams and C. Barbante, Chemical imaging analysis, Elsevier, 2015.

36 P. Mayewski, S. Sneed, S. Birkel, A. Kurbatov and K. Maasch, Holocene warming marked by abrupt onset of longer summers and reduced storm frequency around Greenland, J. Quat. Sci., 2014, 29, 99-104.

37 S. H. Faria, I. Weikusat and N. Azuma, The microstructure of polar ice. Part I: Highlights from ice core research, J. Struct. Geol., 2014, 61, 2-20.

38 S. J. Van Malderen, T. Van Acker and F. Vanhaecke, Submicrometer Nanosecond LA-ICP-MS Imaging at Pixel Acquisition Rates above $250 \mathrm{~Hz}$ via a Low-Dispersion Setup, Anal. Chem., 2020, 92, 5756-5764.

39 M. Šala, V. S. Šelih, C. C. Stremtan and J. T. van Elteren, Analytical performance of a high-repetition rate laser head $(500 \mathrm{~Hz})$ for HR LA-ICP-QMS imaging, J. Anal. At. Spectrom., 2020, DOI: 10.1039/c9ja00421a.

40 M. Bigler, A. Svensson, E. Kettner, P. Vallelonga, M. E. Nielsen and J. P. Steffensen, Optimization of highresolution continuous flow analysis for transient climate signals in ice cores, Environ. Sci. Technol., 2011, 45, 44834489. 